\title{
Unravelling the different functions of protein kinase C isoforms in platelets
}

Citation for published version (APA):

Heemskerk, J. W. M., Harper, M. T., Cosemans, J. M. E. M., \& Poole, A. W. (2011). Unravelling the different functions of protein kinase C isoforms in platelets. Febs Letters, 585(12), 1711-1716. https://doi.org/10.1016/j.febslet.2011.05.017

Document status and date:

Published: 23/06/2011

DOI:

10.1016/j.febslet.2011.05.017

Document Version:

Publisher's PDF, also known as Version of record

Document license:

Taverne

Please check the document version of this publication:

- A submitted manuscript is the version of the article upon submission and before peer-review. There can be important differences between the submitted version and the official published version of record.

People interested in the research are advised to contact the author for the final version of the publication, or visit the DOI to the publisher's website.

- The final author version and the galley proof are versions of the publication after peer review.

- The final published version features the final layout of the paper including the volume, issue and page numbers.

Link to publication

\footnotetext{
General rights rights.

- You may freely distribute the URL identifying the publication in the public portal. please follow below link for the End User Agreement:

www.umlib.nl/taverne-license

Take down policy

If you believe that this document breaches copyright please contact us at:

repository@maastrichtuniversity.nl

providing details and we will investigate your claim.
}

Copyright and moral rights for the publications made accessible in the public portal are retained by the authors and/or other copyright owners and it is a condition of accessing publications that users recognise and abide by the legal requirements associated with these

- Users may download and print one copy of any publication from the public portal for the purpose of private study or research.

- You may not further distribute the material or use it for any profit-making activity or commercial gain

If the publication is distributed under the terms of Article $25 \mathrm{fa}$ of the Dutch Copyright Act, indicated by the "Taverne" license above, 


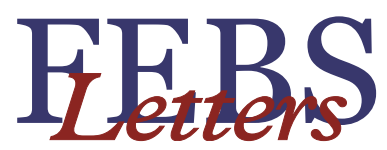

journal homepage: www.FEBSLetters.org

Hypothesis

\title{
Unravelling the different functions of protein kinase $\mathrm{C}$ isoforms in platelets
}

\author{
Johan W.M. Heemskerk ${ }^{\mathrm{a}, *}$, Matthew T. Harper ${ }^{\mathrm{b}}$, Judith M.E.M. Cosemans ${ }^{\mathrm{a}}$, Alastair W. Poole ${ }^{\mathrm{b}, *}$ \\ ${ }^{a}$ Department of Biochemistry, Cardiovascular Research Institute Maastricht, Maastricht University, Maastricht, The Netherlands \\ ${ }^{\mathrm{b}}$ School of Physiology \& Pharmacology, Bristol Heart Institute, Medical Sciences Building, University Walk, Bristol BS8 1TD, United Kingdom
}

\section{A R T I C L E I N F O}

Article history:

Received 14 March 2011

Revised 28 April 2011

Accepted 4 May 2011

Available online 13 May 2011

Edited by Veli-Pekka Lehto

\section{Keywords:}

Platelet

Protein kinase $C$ isoform

Protein phosphorylation

\begin{abstract}
A B S T R A C T
Platelets tightly regulate haemostasis and arterial thrombosis. Protein kinase C (PKC) is involved in most platelet responses implicated in thrombus formation. Recent pharmacological and mouse gene knockout approaches show that the conventional PKC isoforms and the novel PKC isoforms contribute in distinct ways to these platelet responses. We hypothesize that, in platelets and other cells, the characteristic functions of PKC isoforms are established through unique activation mechanisms and unique interacting protein partners, which result in isoform-specific patterns of substrate phosphorylation. For identifying the substrate proteins in a living cell, new methodology is available and discussed.
\end{abstract}

(c) 2011 Federation of European Biochemical Societies. Published by Elsevier B.V. All rights reserved.

\section{Introduction}

Platelets are central to normal haemostasis and arterial thrombosis. Although it has been known for many years that the protein kinase $C$ (PKC) family regulates many cellular functions, recent research provides detailed insight into the roles of individual protein kinase $C$ (PKC) isoforms in the activation of human and mouse platelets. In particular, it has become clear that different isoforms have distinct, non-redundant functions. Hence, the earlier established general concept of PKC structure-function relationships now can be applied to individual PKC isoforms [1,2]. We hypothesize that the functional diversity of PKC isoforms is determined by their variation in structure and phosphorylation, with as a consequence individual temporal and spatial activation patterns. We also discuss strategies for identifying the substrates of each isoform within its appropriate cellular context. Given the ubiquitous expression of most PKC isoforms, the new insights from platelets will help to understand the roles of the kinases in the biology of other mammalian cells.

Members of the subfamilies of conventional PKC (cPKC), novel PKC (nPKC) and atypical PKC (aPKC) isoforms share a well con-

Abbreviations: aPKC, cPKC and nPKC, atypical, conventional and novel protein kinase C respectively; C-KIP, C-kinase interacting protein; DAG, diacylglycerol; GPVI, glycoprotein VI; PS, phosphatidylserine; RACK, receptor for activated C-kinase

* Corresponding authors. Address: Department of Biochemistry, CARIM, Maastricht University, P.O. Box 616, 6200 MD Maastricht, The Netherlands. Fax: +31 43 3884159 (J.W.M. Heemskerk). Bristol Heart Institute, Bristol, United Kingdom. Fax: +44 1173312288 (A.W. Poole).

E-mail addresses: jwm.heemskerk@maastrichtuniversity.nl (J.W.M. Heemskerk), a.poole@bris.ac.uk (A.W. Poole). served catalytic domain with binding sites for ATP and protein substrates (Fig. 1). In all PKC isoforms, the so-called pseudosubstrate site, which docks into the catalytic moiety, needs to be displaced by conformational changes to allow protein kinase activity. This has been most recently demonstrated in the first full-length PKC crystal structure, for PKC $\beta I I$ [3]. In all isoforms, the pseudosubstrate site is located in the region immediately $N$-terminal to the $\mathrm{C} 1$ domain, and contains an Ala instead of Ser/Thr, meaning that it cannot be phosphorylated [1]. Because of these similarities between all PKC isoforms, it is understood that functional diversity should come from variation in their regulatory moieties $[2,4,5]$.

Platelets express the cPKC isoforms, PKC $\alpha$ and $\beta$, which comprise a regulatory moiety with a tandem $\mathrm{C} 1$ domain, capable of binding diacylglycerol (DAG), and a C2 domain, binding $\mathrm{Ca}^{2+}$ and phosphatidylserine (PS) [6-8]. Platelets furthermore express nPKC isoforms, which also have a tandem $\mathrm{C} 1$ domain, but differ by the presence of a C2-like domain that no longer binds $\mathrm{Ca}^{2+}$ (Fig. 1). Whereas PKC $\delta$ and $\theta$ are readily detectable in human and mouse platelets, there expression level of $\mathrm{PKC} \eta$ is unclear [8-11], and expression of $\mathrm{PKC} \varepsilon$ is confined to mouse platelets [8]. Of the aPKC isoforms, which lack a C2 domain and contain a shortened C1 domain that does not bind DAG, only PKC $\zeta$ has been identified in platelets [6,11], although its expression level is uncertain. Considering the structural diversity of the regulatory moieties, we hypothesize that these PKC domains regulate the establishment of unique activation mechanisms and unique sets of interacting protein partners for each isoform, with as a consequence different characteristic functions in the living cell. 


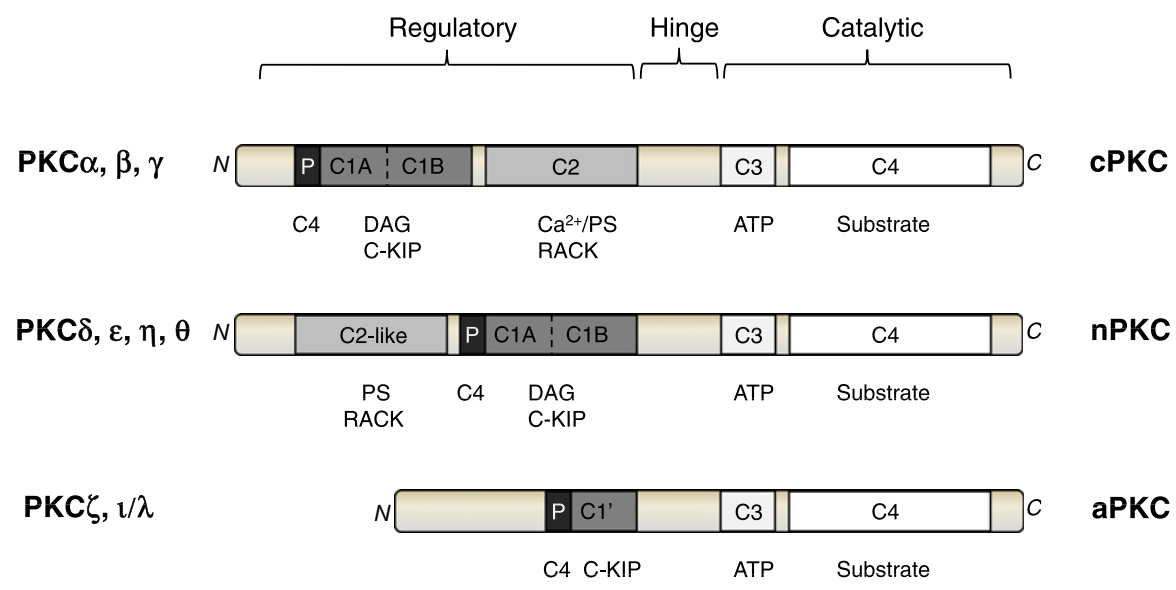

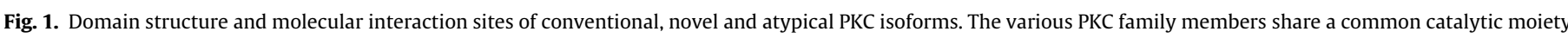

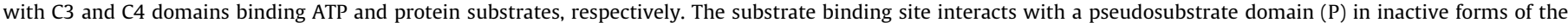

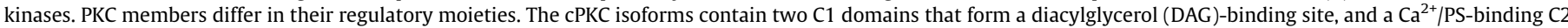

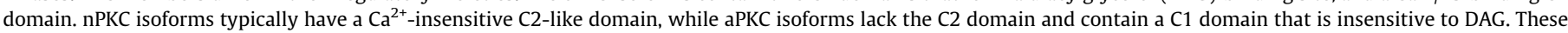

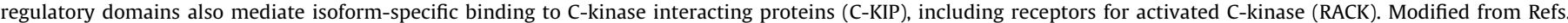
$[7,50]$.

\section{PKC isoform specificity in platelet activation processes}

Signalling by phospholipase C, to produce inositol 1,4,5-trisphosphosphate and diacylglycerol (DAG), has been recognized as a central pathway in almost every platelet response [12]. Thus, PKC activation regulates: (i) platelet adhesiveness by affinity regulation of integrins at the membrane surface; (ii) platelet shape by controlling cytoskeleton dynamics and filopod and lamellipod formation; (iii) secretion of auto- and paracrine agents by promoting exocytosis of storage granules; (iv) synthesis of prostaglandins and thromboxanes; (v) cytosolic $\mathrm{Ca}^{2+}$ fluxes; and (vi) surface membrane exposure of procoagulant PS (Table 1). Accordingly, PKC activation is a crucial step in platelet adhesion to the extracellular matrix and to other blood cells, in platelet-dependent coagulant activity, and in platelet aggregate and thrombus formation. As a whole, the functions of PKC family members however are complex, since they are reported both to positively and negatively regulate integrin activation and secretion, but negatively regulate $\mathrm{Ca}^{2+}$ signalling and procoagulant activity [12,13]. A working hypothesis is therefore that some isoforms of PKC may be responsible for the positive and other isoforms for the negative regulatory effects, although their roles may also differ from one agonist to another.
Investigations using genetically modified mice and supported by studies with PKC isoform-selective inhibitors have yielded detailed insight into the contribution of specific cPKC and nPKC isoforms in these processes (Table 1). Experiments using Prkca ${ }^{-1-}$ and $P r k c b^{-1-}$ mice point to non-redundant positive roles for both cPKC isoforms in the majority of platelet responses. Deficiency in either PKC $\alpha$ or $\mathrm{PKC} \beta$ markedly diminishes collagen-dependent thrombus formation, accompanied by reductions in $\mathrm{Ca}^{2+}$ rise, integrin activation, granule secretion and procoagulant activity $[14,15]$. Inhibitors blocking PKC $\alpha$ and/or PKC $\beta$ isoforms, cause similar effects on human platelets (Table 1). The likely mechanism is reduced signalling via the main collagen receptor, glycoprotein VI (GPVI) [13,16]. Quantitatively, the contribution of PKC $\alpha$ seems to be stronger than that of $\mathrm{PKC} \beta$, which agrees well with the reported relative expression of the two isoforms. PKC $\alpha$ in particular has a major role in regulating platelet dense granule formation and secretion [14,15], whereas $P K C \beta$ is a recognized regulator of integrin-dependent (outside-in) signalling [9].

Given the limited specificity of the pharmacological PKC $\delta$ inhibitor rottlerin, the role of this isoform can best be understood from studies with Prkcd $^{-1-}$ mice. In response to collagen, PKC $\delta$ negatively regulates filopod formation, which may explain its moderate

Table 1

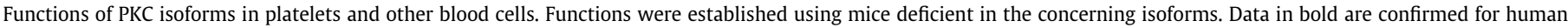
platelets, using pharmacological inhibitors with isoform selectivity: Gö6976 (e.g., blocking PKC $\alpha / \beta), \beta$-inhibitor (PKC $\beta>\alpha)$, rottlerin (PKC $\delta$ ), $\theta$-inhibitor (PKC $\theta$ ).

\begin{tabular}{|c|c|c|c|c|c|c|c|c|c|}
\hline \multirow[t]{2}{*}{ Response (agonist) } & \multicolumn{2}{|c|}{ Conventional } & \multicolumn{4}{|c|}{ Novel } & \multicolumn{2}{|c|}{ Atypical } & \multirow[t]{2}{*}{ Refs. } \\
\hline & $\alpha$ & $\beta$ & $\delta$ & $\varepsilon^{\mathrm{M}}$ & $\eta$ & $\theta$ & $\zeta$ & 1 & \\
\hline \multicolumn{10}{|l|}{ Platelets } \\
\hline Membrane translocation (GPVI, Thr) & + & $\mathrm{o} /+$ & & + & + & + & & & {$[19,36,37]$} \\
\hline Integrin activation (GPVI) & + & + & $\mathbf{o}$ & & & - & & & {$[6,14,17]$} \\
\hline Filopod formation (GPVI) & 0 & & - & & & + & & & {$[15,17]$} \\
\hline Lamellipod formation (fibrinogen) & 0 & + & & & & + & & & {$[9,21,23]$} \\
\hline Exocytosis, $\alpha$ granules (GPVI, Thr) & + & + & $\mathbf{o}$ & & & $-1+$ & & & {$[11,14,15,21]$} \\
\hline Exocytosis, $\delta$ granules (GPVI, Thr) & + & & $-1+$ & + & & 0 & & & {$[6,8,15,17,21]$} \\
\hline Thromboxane production (GPVI, Thr) & & & $-1+$ & & & + & & & {$[10,18,22]$} \\
\hline Calcium flux (GPVI) & + & + & o & & & - & & & {$[13,14,20]$} \\
\hline Procoagulant activity (GPVI) & + & + & 0 & & & - & & & {$[14,20]$} \\
\hline Platelet aggregation (ADP, GPVI, Thr) & + & + & - & + & 0 & $-\left(+^{*}\right)$ & & & {$[8,10,11,14,15,17]$} \\
\hline Thrombus formation (GPVI) & + & + & -10 & 0 & & $-\left(+^{*}\right)$ & & & {$[8,14,15,18,21,22]$} \\
\hline \multicolumn{10}{|l|}{ Other blood cells } \\
\hline Exocytosis lytic granules ( $\mathrm{T}$ cells) & + & & + & & & + & & & {$[25,26,51]$} \\
\hline Exocytosis tertiary granules (neutrophils) & + & & + & & & & & & {$[27]$} \\
\hline Exocytosis (endothelial cells) & & & + & & & & & & {$[52]$} \\
\hline
\end{tabular}

Abbreviations: +, increase; -, decrease; o, no effect; Thr, thrombin. *Reported in one paper. 
negative regulation of platelet aggregation and thrombus formation induced via GPVI $[14,17,18]$. By contrast, PKC $\delta$ has a positive role in thrombin-induced secretion and thromboxane production $[6,18,19]$. The isoform PKC $\varepsilon$, expressed in murine but not human platelets, promotes platelet responses to GPVI but not to thrombin, subsequent to its phosphorylation on tyrosine [8]. One report, assessing $\mathrm{PKC} \eta$ phosphorylation, provides evidence that, in ADPstimulated human platelets, this isoform supports thromboxane production, but not platelet aggregation [10]. Expression effects of PKC $\eta$ and $\zeta$ isoforms have not been confirmed in deficient mice.

The isoform with a most clearly established negative regulation of collagen-dependent thrombus formation is PKC $\theta$, as concluded from the analysis of $\mathrm{Prkcq}^{-1-}$ mice and the use of $\theta$-inhibitor (Table 1). Following GPVI activation, PKC $\theta$ suppresses $\mathrm{Ca}^{2+}$ entry and $\mathrm{Ca}^{2+}$-dependent processes, such as $\alpha$-granule secretion and PS exposure $[14,20]$. As a consequence, this isoform has a markedly suppressive role in collagen-dependent thrombus formation $[14,21]$. By contrast, in thrombin-stimulated platelets, PKC $\theta$ positively contributes to granule secretion, thromboxane production and aggregation [11,22]. PKC $\theta$ also promotes lamellipod formation of platelets on fibrinogen $[21,23]$. These findings highlight the differences in regulation of platelet activation via protein tyrosine kinase-dependent pathways (GPVI) and G-protein coupled receptor pathways (ADP and thrombin receptors). Involvement of the latter may explain why one publication has denoted a positive role for PKC $\theta$ in thrombus stabilization [22] and why Prkcq $^{-1-}$ mice show a prolonged tail bleeding time [11].

Interestingly, pan-PKC inhibitors such as Ro-318425 and GF109203X have profound inhibitory effects on platelet aggregation, integrin activation and secretion, but enhance agonist-induced $\mathrm{Ca}^{2+}$ responses and procoagulant activity [13,14,24]. In general, these effects are larger in comparison to single gene ablation. This may point to (partial) redundancy in action mechanism between different (related) PKC isoforms, but data from multi-gene knockouts supporting this are lacking yet. Alternative explanations can not be ruled out, e.g., that pan-inhibitors abolish cross-talk or cross-network phosphorylation events involving different PKC isoforms.

When analysing genes using a whole mouse gene modification, or ablation, approach, it is important to bear in mind secondary consequences of genetic modification, for instance changes in expression of related genes and developmental defects. For this reason it is essential to verify that other key regulators of the studied signalling pathway are expressed to normal levels. It is also important to assess platelet morphology and structure. One example that highlights this is that ablation of the Prkca gene for PKC $\alpha$ causes a marked reduction in numbers of platelet dense granules, but not $\alpha$-granules [15].

Data from other blood cells are still scarce, but a few reports show that granule secretion in cytotoxic $\mathrm{T}$ cells and neutrophils is mediated by PKC $\alpha$ (as in platelets) and by PKC $\delta$ [25-27]. Taken together, members of the cPKC and nPKC subfamilies appear to have, at least in part, non-redundant roles in cytosolic signalling processes. In particular for platelets stimulated via GPVI, the CPKC isozymes act in a stimulatory manner, whereas the nPKC isoforms have a suppressive effect on platelet function and thrombus formation.

\section{Phosphorylation as a prerequisite for activation of PKC isoforms}

Phosphorylation of PKC is an important control mechanism of kinase activity, e.g., by altering the accessibility of protein substrates to the kinase domain. Different PKC isoforms are likely to be subjected to dissimilar phosphorylation events. According to the classical scheme, a three-step sequence of phosphorylation events during maturation is required for producing active PKC forms $[28,29]$. For PKC $\beta$ it was established that a conserved Thr in the catalytic moiety around amino acid residue 500 becomes phosphorylated by phosphoinositide-dependent kinase-1 (PDK1), after which two Thr or Ser residues around amino acid residue 650 are phosphorylated by mammalian target of rapamycin complex 2 (mTORC2) [30,31]. This scheme may also be applicable to other CPKC and nPKC family members, which have corresponding phosphorylation sites (Supplementary Table 1).

Recent work on platelets and other cells has shed new light on this phosphorylation pattern in particular for nPKC isoforms. In platelets, it is reported that agonist stimulation leads to phosphorylation of the 'PDK1 site' in the substrate-binding domain of PKC $\delta$ at $\mathrm{Thr}^{505}$ and PKC $\theta$ at $\mathrm{Thr}^{538}[10,22,32]$, as has been observed in Tlymphocytes previously [33]. Furthermore, these nPKC isoforms show other, unique tyrosine phosphorylation events. Protein kinases of the Src family mediate tyrosine phosphorylation of PKC $\delta$ on at least two different sites, $\mathrm{Tyr}^{311}$ and $\mathrm{Tyr}^{565}$, after platelet stimulation with phorbol ester or other agonists [32,34]. In human platelets tyrosine phosphorylation of $\mathrm{PKC} \delta$ is transient upon activation, while in mouse platelets it is sustained [8]. For this isoform, it was established that agonist-induced phosphorylation regulates the kinase activity, but not the translocation from cytosol to membrane [34]. In mouse platelets, PKCE seems to be constitutively phosphorylated on tyrosine [8]. In human platelets, however, phosphorylation of PKC $\theta$ at Tyr $^{90}$ in the regulatory domain can be evoked by GPVI- or integrin-induced stimulation [23]. Similarly in T-cells, PKC $\theta$ activation depends on tyrosine phosphorylation by Src family kinases [35]. Importantly, tyrosine phosphorylation of nPKC species may provide a means for isoform-specific signalling, when this allows recruitment of the phosphorylated PKC to $\mathrm{SH} 2$ or PTB domain-containing proteins, for instance such as present in the assembling GPVI signalosome.

\section{Spatio-temporal activation and interaction patterns of PKC isoforms}

In vitro, the PKC family members show broadly overlapping substrate specificities, in agreement with the high sequence identity of their catalytic moieties. The recognition that they have non-redundant roles in many cellular functions points to a well-controlled regulation of their localisation and perhaps temporal activation within the cell, to allow distinct ways of signal propagation. Here, we hypothesise that even within the small volume of a platelet (2-3 $\mu \mathrm{m}$ in diameter, $8-12 \mathrm{fl}$ in volume), different localisation and activation patterns determine the precise roles of PKC family members (Fig. 2). Nevertheless, partial redundancy in action mechanism between different (related) PKC isoforms may exist.

The lack of a functional $\mathrm{Ca}^{2+}$ binding site in nPKC isoforms suggests a difference in activation mechanism in comparison to cPKC, in particular in response to $\mathrm{Ca}^{2+}$-mobilising, DAG-producing agonists. Yet, in thrombin-stimulated platelets almost all isoforms translocate to the plasma membrane, suggesting an integrated mechanism of kinase activation [19,36,37]. PKC $\delta$ may be an exception here, in that it does not translocate in response to thrombin itself [36], but only after integrin engagement [19]. The classical view is that membrane translocation and DAG binding to the regulatory domain releases auto-inhibition and exposes the PKC active site. However, common translocation does not imply translocation to identical membrane sites or membrane protein complexes. Different sites of membrane interaction furthermore may imply different temporal patterns of activation and stabilization of the kinase, and different interaction sites for other intracellular proteins. Novel, higher resolution live cell imaging approaches are needed to confirm this concept. 


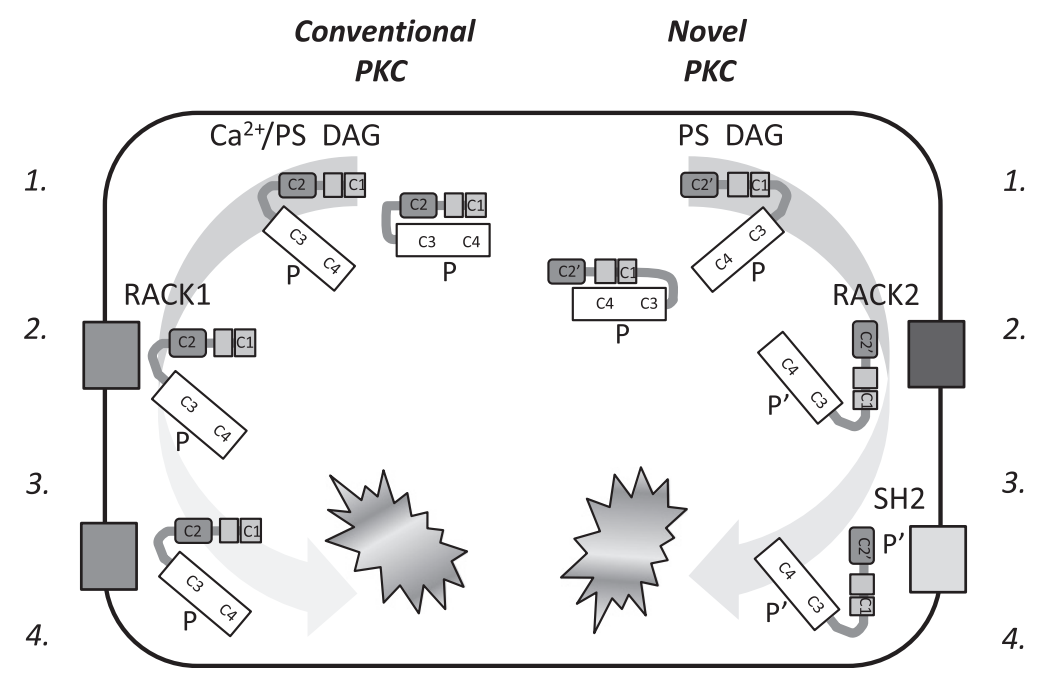

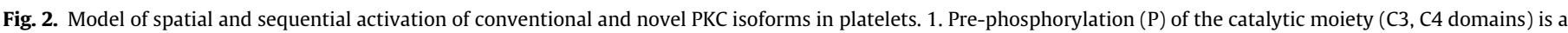

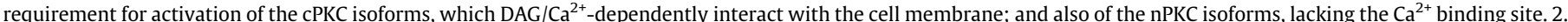

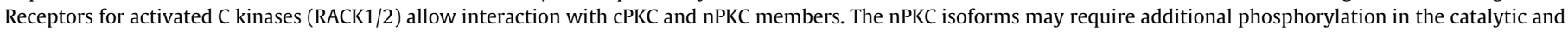

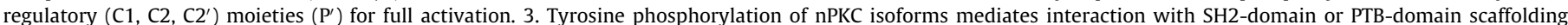

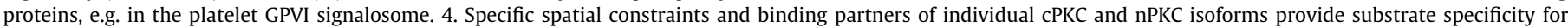
phosphorylation of target proteins.

Receptors for activated C kinase (RACK) were one of the first recognised anchoring sites for activated PKC. Two forms are distinguished, i.e., RACK1 which binds to PKC isoforms $\alpha \beta$, and RACK2 with a higher affinity for $\mathrm{PKC} \varepsilon$ [38]. It is considered that these anchoring proteins direct CPKC and nPKC isoforms to distinct locations in the plasma membrane, and thereby target interactions with specific substrates. In platelets, peptides inhibiting the binding of PKC $\delta, \eta$ or $\theta$ to RACK have been used to study the roles of these isoforms in platelet function $[10,18,22]$. Which of the RACK species were targeted was however not determined. In addition to RACK, many other interacting proteins for inactive or active PKC isoforms have been identified in a variety of cell systems, as summarised before [39]. Several of these may also serve as scaffolding proteins. Notably, tyrosine phosphorylation of nPKCs such as PKC $\theta$ may facilitate the interaction with $\mathrm{SH} 2$-domain signalling proteins and explain their interaction with protein tyrosine kinases, Btk and Syk [23,40].

\section{Identifying the in vivo substrates of PKC isoforms}

Despite a high sequence identity of the catalytic domains of PKC, the at least partial non-redundancy of different PKC isoforms in cell function implies that these will phosphorylate different sets of protein substrates in vivo. Identifying the substrates of the individual PKC isoforms, in the living cell, is therefore a major goal of PKC biology in general, and of platelet biology in particular. A few targets of PKC in platelets are known for many years, such as pleckstrin [41] and myristoylated alanine-rich C kinase substrate (MARCKS) [42]. Unspecified isoforms phosphorylate proteins of the cytosolic SNARE complex that regulates granule secretion [43]. In general, though, very limited information is available on the precise substrate proteins of individual CPKC and nPKC isoforms and the relationship of this to cellular function.

Identification of novel PKC substrates involves either targeted studies on a particular protein of interest, from knowledge about other cell types or bioinformatic predictions, or proteomics studies where multiple proteins are screened. The classical biochemical approach identifies protein substrates by incubating cell lysates with a purified PKC isoform in the presence of $\mathrm{MgCl}_{2}$ and $\left[\gamma-{ }^{32} P\right]$ ATP, followed by substrate identification by two-dimensional gel electrophoresis and mass spectroscopy [44,45]. Obvious drawbacks are the interference of protein phosphatases and other protein kinases such as protein kinase $\mathrm{D}$, which become activated in a PKC-dependent manner [46]. Furthermore, this in vitro approach may identify substrates that, in a live-cell setting, would not physically interact with the concerning kinase isoform.

More recently, a promising chemical-genetic approach to identifying kinase substrates has been pioneered by the Shokat group [47]. It makes use of the conserved ATP-binding domains within protein kinases, including a conserved Met residue that comes into close proximity with the $N^{6}$ position of ATP [44]. Mutation of this Met to an amino acid residue with a smaller side chain (Gly or Ala) does not abolish kinase activity, but it allows $N^{6}$-modified ATP analogues with bulky side chains, such as $N^{6}$-benzoyl ATP, to access to the ATP-binding pocket. If $N^{6}$-benzoyl $\left[\gamma_{-}{ }^{32} P\right]$ ATP is used as substrate in place of ATP, only the mutant kinase will be able to utilise this and only direct kinase substrates will be radiolabelled. The labelled substrates are then identified by gel electrophoresis and mass spectroscopic techniques. The advantage of this modified approach is a reduced background phosphorylation and labelling of only direct substrates of the kinase. This method has been used to identify novel, direct substrates of the kinase Erk2 [48]. An improvement of this method is to use $N^{6}$-benzoyl ATP $\gamma \mathrm{S}$, which labels the substrate with a unique thiophosphate moiety that can be purified on an iodo-acetyl resin before substrate identification [49].

Another possible route to identifying PKC substrates comes from immuno-precipitating complexes containing individual isoforms with their substrates, followed by proteomic analysis. For instance, this approach has been useful to identify $\operatorname{PKC} \delta$ as a substrate of the tyrosine kinase Lyn [18].

A limitation of substrate identification using cell lysates is the promiscuity of kinases for substrate proteins in vitro, when freed from the regulatory constrains present in vivo. Particularly, PKC isoforms have largely overlapping substrate specificities in vitro. One approach to demonstrate that a candidate substrate is phosphorylated in intact cells is to use phospho-motif antibodies. Such antibodies are directed to phospho-Ser or phospho-Thr within conserved, consensus phosphorylation sites of PKC [45]. PKC substrate motifs are predicted from known substrates or by screening of peptide libraries. Hence, antibodies raised against the generalized PKC consensus sequence, (Lys/Arg) ${ }_{1-3}-X-(\mathrm{pSer} / \mathrm{pThr})-Y$-(Lys/Arg) $)_{1-3}$, 
where $X=$ any amino acid, and $Y=$ a hydrophobic amino acid [5], are used to detect potentially PKC-phosphorylated proteins in platelets, which can be confirmed by subsequent mass spectroscopic analysis. The consensus sequence varies only slightly between different PKC isoforms, meaning that antibodies may recognise the phosphorylated substrates of multiple isoforms. Furthermore, because the consensus sequence for PKC is similar to those for the related protein kinases, PKA and PKB [5], potential involvement of the latter kinases needs to be excluded.

Knockout mouse strains have been valuable to confirm that substrates can be targets of a specific PKC isoform within the cellular context. For example, PKC $\alpha^{-1-}$ mouse platelets display impaired agonist-induced phosphorylation of SNAP23 (a member of the SNARE complex) [15]. Platelets from $\mathrm{PKC}^{-1-}$ mice show altered phosphorylation of vasodilator-stimulated phosphoprotein (VASP), a critical regulator of actin cytoskeleton dynamics, which can explain the inhibitory role of PKC $\delta$ on filopod formation [17]. In $\mathrm{PKC} \varepsilon^{-1-}$ platelets, GPVI-induced phosphorylation of pleckstrin is impaired [8]. Finally, PKC $\theta^{-1-}$ platelets show reduced syntaxin4 phosphorylation (also in the SNARE complex) [22], and phosphorylation of WASP-interacting protein, which participates in the regulation of F-actin nucleation and hence the dynamics of the actin cytoskeleton [23]. However, in all these instances there is incomplete demonstration that the substrate proteins are directly phosphorylated by the proposed isoforms. Proof should come from a convergence of multiple lines of evidence from studies in vitro and in intact cells, described above. Further confirmation should come from high-resolution imaging techniques to identify the precise spatial areas of PKC isoform localisation in vivo by super-resolution fluorescence microscopy and electron-microscopic tomography with immuno-gold labelling.

\section{Conclusions}

We are beginning to understand the distinct, key roles of PKC isoforms in platelet function and the molecular mechanisms of PKC activation and regulation by which these are achieved. These mechanisms seem to differ from isoform to isoform, although partial redundancy may exist. Differences however are recognizable in activation patterns, interacting protein partners and molecular substrates. Future challenges are knowledge of the molecular substrates of the isoforms, and thorough understanding of their spatio-temporal signalling patters.

\section{Conflict of interest declaration}

The authors have declared that no conflict of interest exists.

\section{Appendix A. Supplementary data}

Supplementary data associated with this article can be found, in the online version, at doi:10.1016/j.febslet.2011.05.017.

\section{References}

[1] Hug, H. and Sarre, T.F. (1993) Protein kinase C isoenzymes, divergence in signal transduction? Biochem. J. 291, 329-343.

[2] Steinberg, S.F. (2004) Structural basis of protein kinase C isoform function Physiol. Rev. 88, 1341-1378.

[3] Leonard, T.A., Rozycki, B., Saidi, L.F., Hummer, G. and Hurley, J.H. (2011) Crystal structure and allosteric activation of protein kinase C $\beta$ II. Cell 144, 55-66.

[4] Mellor, H. and Parker, P.J. (1996) The extended protein kinase C superfamily. Biochem. J. 332, 281-292.

[5] Aitken, A. (1999) Protein consensus sequence motifs. Mol. Biotech. 12, 241 253.

[6] Murugappan, S., Tuluc, F., Dorsam, R.T., Shankar, H. and Kunapuli, S.P. (2004) Differential role of protein kinase $C \delta$ isoform in agonist-induced dense granule secretion in human platelets. J. Biol. Chem. 279, 2360-2367.
[7] Harper, M.T. and Poole, A.W. (2010) Diverse functions of protein kinase C isoforms in platelet activation and thrombus formation. J. Thromb. Haemost. 8 454-462.

[8] Pears, C.J., Thornber, K., Auger, J.M., Hughes, C.E., Grysielska, B., Protty, M.B., Pearce, A.C. and Watson, S.P. (2008) Differential roles of the PKC novel isoforms, $\mathrm{PKC} \delta$ and $\mathrm{PKC} \varepsilon$, in mouse and human platelets. PlosOne 3, e3793.

[9] Buensuceso, C.S., Obergfell, A., Soriani, A., Eto, K., Kiosses, W.B., Arias-Salgado, E.G., Kawakami, T. and Shattil, S.J. (2005) Regulation of outside-in signaling in platelets by integrin-associated protein kinase C $\beta$. J. Biol. Chem. 280, 644-653.

[10] Bynagari, Y.S., Nagy, B., Tuluc, F., Bhavareju, K., Kim, S., Vijayan, K.V. and Kunapuli, S.P. (2009) Mechanism of activation and functional role of protein kinase $\mathrm{Ch}$ in human platelets. J. Biol. Chem. 284, 13413-134121.

[11] Cohen, S., Braiman, A., Shubinsky, G., Ohayon, A., Altman, A. and Isakov, N. (2009) PKC $\theta$ is required for hemostasis and positive regulation of thrombininduced platelet aggregation and $\alpha$-granule secretion. Biochem. Biophys. Res. Commun. 385, 22-27.

[12] Siess, W. (1989) Molecular mechanisms of platelet activation. Physiol. Rev. 69, 58-178.

[13] Strehl, A., Munnix, I.C., Kuijpers, M.J., van der Meijden, P.E., Cosemans, J.M., Feijge, M.A., Nieswandt, B. and Heemskerk, J.W. (2007) Dual role of platelet protein kinase $C$ in thrombus formation: stimulation of pro-aggregatory and suppression of procoagulant activity in platelets. J. Biol. Chem. 282, 70467055.

[14] Gilio, K. et al. (2010) Functional divergence of platelet PKC isoforms in thrombus formation on collagen. J. Biol. Chem. 285, 23410-23419.

[15] Konopatskaya, O. et al. (2009) PKC $\alpha$ regulates platelet granule secretion and thrombus formation in mice. J. Clin. Invest. 119, 399-407.

[16] Heemskerk, J.W., Kuijpers, M.J., Munnix, I.C. and Siljander, P.R. (2005) Platelet collagen receptors and coagulation. A characteristic platelet response as possible target for antithrombotic treatment. Trends Cardiovasc. Med. 15, 8692.

[17] Pula, G., Schuh, K., Nakayama, K., Nakayama, K.I., Walter, U. and Poole, A.W. (2006) $\mathrm{PKC} \delta$ regulates collagen-induced platelet aggregation through inhibition of VASP-mediated filopodia formation. Blood 108, 4035-4044.

[18] Chari, R. et al. (2009) Protein kinase $C \delta$ differentially regulates platelet functional responses. Arterioscler. Thromb. Vasc. Biol. 29, 699-705.

[19] Yacoub, D., Theoret, J.F., Villeneuve, L., Abou-Saleh, H., Mourad, W. and Allen, B.G. (2006) Essential role of protein kinase $C \delta$ in platelet signaling, $\alpha_{\mathrm{IIb}} \beta_{3}$ activation, and thromboxane $A_{2}$ release. J. Biol. Chem. 281, 3002430035.

[20] Harper, M.T. and Poole, A.W. (2010) Protein kinase C $\theta$ negatively regulates store-independent $\mathrm{Ca}^{2+}$ entry and phosphatidylserine exposure downstream of glycoprotein VI in platelets. J. Biol. Chem. 285, 19865-19873.

[21] Hall, K.J., Harper, M.T., Gilio, K., Cosemans, J.M., Heemskerk, J.W. and Poole, A.W. (2008) Genetic analysis of the role of protein kinase $C \theta$ in platelet function and thrombus formation. Plos One 3, e3277.

[22] Nagy, B., Bhavaraju, K., Getz, T., Bynagari, Y.S., Kim, S. and Kunapuli, S.P. (2009) Impaired activation of platelets lacking protein kinase $\mathrm{C} \theta$ isoform. Blood 113 , 2557-2567.

[23] Soriani, A., Moran, B., De Virgilio, M., Kawakami, T., Altman, A., Lowell, C., Eto, K. and Shattil, S.J. (2006) A role for PKC $\theta$ in outside-in $\alpha_{\mathrm{Ib}} \beta_{3}$ signaling. J. Thromb. Haemost. 4, 648-655.

[24] Watson, S.P., McNally, J., Shipman, L.J. and Godfrey, P.P. (1988) The action of the protein kinase $C$ inhibitor, staurosporine, on human platelets: evidence against a regulatory role for protein kinase $\mathrm{C}$ in the formation of inositol trisphosphate by thrombin. Biochem. J. 249, 345-350.

[25] Grybko, M.J., Pores-Fernando, A.T., Wurth, G.A. and Zweifach, A. (2007) Protein kinase $\mathrm{C}$ activity is required for cytotoxic $\mathrm{T}$ cell lytic granule exocytosis, but the theta isoform does not play a preferential role. J. Leukoc. Biol. 81, 509-519.

[26] Ma, J.S., Haydar, T.F. and Radoja, S. (2008) Protein kinase C $\delta$ localizes to secretory lysosomes in $\mathrm{CD}^{+} \mathrm{CTL}$ and directly mediates TCR signals leading to granule exocytosis-mediated cytotoxicity. J. Immunol. 181, 4716-4722.

[27] Chakrabarti, S., Zee, J.M. and Patel, K.D. (2006) Regulation of matrix metalloproteinase-9 (MMP-9) in TNF-stimulated neutrophils: novel pathways for tertiary granule release. J. Leukoc. Biol. 79, 214-222.

[28] Parekh, D.B., Ziegler, W. and Parker, P.J. (2000) Multiple pathways control protein kinase C phosphorylation. EMBO J. 19, 496-503.

[29] Newton, A.C. (2003) Regulation of the ABC kinases by phosphorylation: protein kinase $C$ as a paradigm. Biochem. J. 370, 361-371.

[30] Pearce, L.R., Komander, D. and Alessi, D.R. (2010) The nuts and bolts of AGC protein kinases. Nat. Rev. Mol. Cell Biol. 11, 9-22.

[31] Ikenoue, T., Inoki, K., Yang, Q., Zhou, X. and Guan, K.L. (2008) Essential function of TORC2 in PKC and Akt turn motif phosphorylation, maturation and signalling. EMBO J. 27, 1919-1931.

[32] Murugappan, S., Chari, R.P., Jin, J. and Kunapuli, S.P. (2009) Differential regulation of threonine and tyrosine phosphorylations on protein kinase $C \delta$ by G-protein-mediated pathways in platelets. Biochem. J. 417, 113-120.

[33] Lee, K.Y., D’Acquisto, F., Hayden, M.S., Shim, J.H. and Ghosh, S. (2005) PDK1 nucleates $\mathrm{T}$ cell receptor-induced signaling complex for NFKB activation. Science 308, 114-118.

[34] Hall, K.J., Jones, M.L. and Poole, A.W. (2007) Coincident regulation of PKC $\delta$ in human platelets by phosphorylation of Tyr311 and Tyr565 and phospholipase C signalling. Biochem. J. 406, 501-509.

[35] Zanin-Zhorow, A. et al. (2010) Protein kinase C- $\theta$ mediates negative feedback on regulatory $\mathrm{T}$ cell function. Science $328,372-376$. 
[36] Baldassare, J.J., Henderson, P.A., Burns, D., Loomis, C. and Fisher, G.J. (1992) Translocation of protein kinase $C$ isozymes in thrombin-stimulated human platelets: correlation with 1, 2-diacylglycerol levels. J. Biol. Chem. 267, 1558515590.

[37] Wang, F., Naik, U.P., Ehrlich, Y.H., Osada, S.I., Ohno, S. and Kornecki, E. (1995) Stimulatory antibody-induced activation and selective translocation of protein kinase C isoenzymes in human platelets. Biochem. J. 311, 401-406.

[38] Mochly-Rosen, D. (1995) Localization of protein kinases by anchoring proteins, a theme in signal transduction. Science 268, 247-251.

[39] Poole, A.W., Pula, G., Hers, I., Crosby, D. and Jones, M.L. (2004) PKC-interacting proteins: from function to pharmacology. Trends Pharmacol. Sci. 25, 528-535.

[40] Crosby, D. and Poole, A.W. (2002) Interaction of Bruton's tyrosine kinase and protein kinase $\mathrm{C} \theta$ in platelets. Cross-talk between tyrosine and serine/ threonine kinases. J. Biol. Chem. 277, 9958-9965.

[41] Tyers, M., Rachubinski, R.A., Stewart, M.I., Varrichio, A.M., Shorr, R.G., Haslam, R.J. and Harley, C.B. (1988) Molecular cloning and expression of the major protein kinase $C$ substrate of platelets. Nature 333, 470-473.

[42] Hartwig, J.H., Thelen, M., Rosen, A., Janmey, P.A., Nairn, A.C. and Aderem, A. (1992) MARCKS is an actin filament crosslinking protein regulated by protein kinase $C$ and calcium-calmodulin. Nature 356, 618-622.

[43] Flaumenhaft, R. (2003) Molecular basis of platelet granule secretion. Arterioscler. Thromb. Vasc. Biol. 23, 388-396.

[44] Johnson, S.A. and Hunter, T. (2005) Kinomics: methods for deciphering the kinome. Nat. Methods 2, 17-25.
[45] Berwick, D.C. and Tavere, J.M. (2004) Identifying protein kinase substrates: hunting for the organ-grinder's monkeys. Trends Biochem. Sci. 29, 227-232.

[46] Stafford, M.J., Watson, S.P. and Pears, C.J. (2003) PKD: a new protein kinase Cdependent pathway in platelets. Blood 15, 1392-1399.

[47] Bishop, A et al. (2000) Unnatural ligands for engineered proteins: new tools for chemical genetics. Annu. Rev. Biophys. Biomol. Struct. 29, 577-606.

[48] Eblen, S.T., Kumar, N.V., Shah, K., Henderson, M.J., Watts, C.K., Shokat, K.M. and Weber, M.J. (2003) Identification of novel ERK2 substrates through use of an engineered kinase and ATP analogs. J. Biol. Chem. 278, 14926-14935.

[49] Blethrow, J.D., Glavy, J.S., Morgan, D.O. and Shokat, K.M. (2008) Covalent capture of kinase-specific phosphopeptides reveals Cdk1-cyclin B substrates. Proc. Natl. Acad. Sci. USA 105, 1442-1447.

[50] Rosse, C., Linch, M., Kermorgant, S., Cameron, A.J., Boeckeler, K. and Parker, P.J (2010) PKC and the control of localized signal dynamics. Nat. Rev. Mol. Cell Biol. 11, 103-112.

[51] Pores-Fernando, A.T., Ranaghan, M.Y. and Zweifach, A. (2009) No specific subcellular localization of protein kinase $C$ is required for cytotoxic $T$ cell granule exocytosis. J. Biol. Chem. 284, 25107-25115.

52] Lorenzi, O, Frieden, M., Villemin, P., Fournier, M., Foti, M. and Vischer, U.M. (2008) Protein kinase $C-\delta$ mediates von Willebrand factor secretion from endothelial cells in response to vascular endothelial growth factor (VEGF) but not histamine. J. Thromb. Haemost. 6, 1962-1969. 